\title{
Building capacity in biodiversity monitoring at the global scale
}

\author{
Dirk S. Schmeller, ${ }^{1,2}$, Monika Böhm³ ${ }^{3}$, Christos Arvanitidis ${ }^{4}$, Shannon \\ Barber-Meyer ${ }^{5}$, Neil Brummitt ${ }^{6}$, Mark Chandler ${ }^{7}$, Eva \\ Chatzinikolaou $^{3}$, Mark J. Costello ${ }^{8}$, Hui Ding ${ }^{9}$, Jaime García- \\ Moreno $^{10}$, Mike Gill ${ }^{11}$, Peter Haase ${ }^{12,13}$, Miranda Jones ${ }^{14,15}$, Romain \\ Juillard $^{16}$, William E. Magnusson ${ }^{17}$, Corinne S. Martin ${ }^{14}$, Melodie \\ McGeoch ${ }^{18}$, Jean-Baptiste Mihoub ${ }^{1}$, Nathalie Pettorelli ${ }^{3}$, Vânia \\ Proença $^{19}$, Cui Peng ${ }^{9}$, Eugenie Regan ${ }^{20}$, Ute Schmiedel ${ }^{21}$, John P. \\ Simaika ${ }^{12}$, Lauren Weatherdon ${ }^{14}$, Carly Waterman ${ }^{3}$, Haigen $X u^{9}$, \\ Jayne Belnap ${ }^{22}$
}

1. Helmholtz Center for Environmental Research - UFZ, Department of Conservation Biology, Permoserstrasse 15, 04318 Leipzig, Germany, ds@dieschmellers.de

2. ECOLAB, Université de Toulouse, CNRS, INPT, UPS, Toulouse, France.

3. Institute of Zoology, Zoological Society of London, Regent's Park, NW1 4RY London, UK

4. Institute of Marine Biology, Biotechnology and Aquaculture, Hellenic Centre for Marine Research (HCMR), P.O. Box 2214, 71003 Heraklion Crete, Greece

5. Research completed at: Scripps Institute of Oceanography, University of California, San Diego, USA; Current address: US Geological Survey, Northern Prairie Wildlife Research Center, Jamestown, ND, USA

6. Natural History Museum, Cromwell Road, London, SW7 5BD

7. Earthwatch Institute, Boston, MA 02134, USA

8. Institute of Marine Science, University of Auckland, Auckland 1142, New Zealand.

9. Nanjing Institute of Environmental Sciences, Ministry of Environmental Protection, Nanjing 210042, P. R. China

10. ESiLi, Het Haam 16, 6846 KW Arnhem, Netherlands

11. Canadian High Arctic Research Station, Aboriginal Affairs and Northern Development Canada, 15 Eddy Street, Hull, Quebec, Canada, K1A 0M4

12. Senckenberg Research Institute and Natural History Museum, Department of River Ecology and Conservation, Clamecystraße 12, 63571 Gelnhausen

13. University of Duisburg-Essen, Faculty of Biology, Essen, Germany

14. United Nations Environment World Conservation Monitoring Centre, 219 Huntingdon Road, Cambridge, CB3 ODL, UK

15. Changing Ocean Research Unit and Nereus Program, Fisheries Centre, University of British Columbia, Canada.

16. Muséum National d'Histoire Naturelle, Département Ecologie et Gestion de la Biodiversité, UMR 7204 MNHN-CNRS 'Centre d'Ecologie et des Sciences de la Conservation, 55 rue Buffon, 75005 Paris

17. Instituto Nacional de Pesquisas da Amazônia, Av. Efigênio Sales, 2239, Aleixo, CEP: 69067-375 - Manaus, AM, Brasil.

18. School of Biological Sciences, Monash University, Clayton 3800, Victoria, Australia 
19. MARETEC, Instituto Superior Técnico, Universidade de Lisboa, Av. Rovisco Pais 1, 1049-001 Lisboa, Portugal

20. The Biodiversity Consultancy, 3E King's Parade, Cambridge, CB2 1SJ, UK

21. University of Hamburg, Biocentre Klein Flottbek and Botanical Garden, Ohnhorststrasse 18, 22609 Hamburg, Germany

22. U.S. Geological Survey, Southwest Biological Science Center, Moab, UT 84532 U.S.A. 
Abstract

Human-driven global change is causing ongoing declines in biodiversity worldwide. In order to address these declines, decision-makers need accurate assessments of the status of and pressures on biodiversity. However, these are heavily constrained by incomplete and uneven spatial, temporal and taxonomic coverage. For instance, data from regions such as Europe and North America are currently used overwhelmingly for large-scale biodiversity assessments due to lesser availability of suitable data from other, more biodiversity-rich, regions. These data-poor regions are often those experiencing the strongest threats to biodiversity, however. There is therefore an urgent need to fill the existing gaps in global biodiversity monitoring. Here, we review current knowledge on best practice in capacity building for biodiversity monitoring and provide an overview of existing means to improve biodiversity data collection considering the different types of biodiversity monitoring data. Our review comprises insights from work in Africa, South America, Polar Regions and Europe; in governmentfunded, volunteer and citizen-based monitoring in terrestrial, freshwater and marine ecosystems. The key steps to effectively building capacity in biodiversity monitoring are: identifying monitoring questions and aims; identifying the key components, functions, and processes to monitor; identifying the most suitable monitoring methods for these elements, carrying out monitoring activities; managing the resultant data; and interpreting monitoring data. Additionally, biodiversity monitoring should use multiple approaches including extensive and intensive monitoring through volunteers and professional scientists but also harnessing new technologies. Finally, we call on the scientific community to share biodiversity monitoring data, knowledge and tools to ensure the accessibility, interoperability, and reporting of biodiversity data at a global scale. 
Keywords: biodiversity monitoring, paraecologists, citizen science, remote sensing, new technologies 


\section{Introduction}

Human-driven global change is causing ongoing declines in biodiversity worldwide, as shown in recent assessments of progress towards international biodiversity policy targets (e.g. Convention on Biological Diversity (CBD); Butchart et al. 2010; Tittensor et al. 2014). However, these assessments were constrained by incomplete and uneven spatial, temporal and taxonomic coverage of the underlying biodiversity data. For instance, data from Europe and North America contribute disproportionately to such assessments (e.g., the Living Planet Index (LPI): see Collen et al. 2009; Loh et al. 2005; Pereira et al. 2010). While improvements in the calculation of the LPI have been made to address the bias towards more developed countries (McRae et al. 2016), suitable data is still lacking in the most biodiversity-rich areas, where the strongest negative pressures often occur (McRae et al. 2012). Effective capacity building is therefore essential to fill data gaps in these regions systematically (Böhm and Collen 2015). These data gaps are similar across terrestrial, freshwater and marine systems. For example, ocean sampling shows a strong bias in sampling effort and data availability towards temperate regions in the northern hemisphere (www.iobis.org, (Mora et al. 2008; Costello et al. in press). Despite freshwater and terrestrial systems being more accessible to humans than most ocean environments, and terrestrial species monitoring in particular having a long-standing history (Marsh and Trenham 2008; Schmeller 2008; 2009; 2012b), biases towards temperate Northern hemisphere regions persist here as well.

There are many obstacles to developing monitoring capacity at the global scale (Schmeller et al. 2015). Other than in a few localized areas, the current state of biodiversity monitoring is not sufficient to detect the trends and status of most species and habitats or for attributing drivers to these trends (Hoffmann et al. 2014). Baseline 
information is currently lacking for many species and habitats, particularly in the marine realm (Lotze and Worm 2009) and within lower trophic levels. In order to obtain best possible data on the status and trends of biodiversity and the pressures affecting it, a cross-scale perspective (local to global) is needed to devise, deliver, and support capacity building in biodiversity monitoring across systems (terrestrial, freshwater, marine), geographic regions, and taxa (Schmeller et al. 2015). Such efforts are also important to support international conservation policy by providing coherent, standardized, and harmonized global data sets (Schmeller and Bridgewater 2016). The Global Earth Observation System of Systems (GEOSS) aims to fill knowledge gaps in earth observation by linking up existing resources and facilitating the creation of new monitoring initiatives (Conference of Parties COP 10 decision X/7; http://www.cbd.int/decision/cop/?id=12273). GEOSS is being developed by the Group on Earth Observation (GEO). The Group on Earth Observation - Biodiversity Observation Network (GEO BON) is one of nine societal-benefit areas under GEO and is the main global facilitator network for biodiversity monitoring. GEO BON is focused on building capacity and facilitating the tracking of biodiversity change in the context of progress towards global biodiversity policy targets, thus allowing the evaluation of the current status and future trends of global biodiversity. The efforts to implement GEO BON have been recognized as important by the Parties to the Convention on Biological Diversity (COP 9 decision IX/15; http://www.cbd.int/decision/cop/default.shtml?id=11658) and by the Intergovernmental Platform on Biodiversity and Ecosystem Services (IPBES).

Here, we develop a framework for capacity building in biodiversity monitoring. We define capacity building within the context of biodiversity monitoring and as outlined by the Convention on Biological Diversity (CBD). We review how the type of monitoring program may affect on-the-ground capacity building in terrestrial, freshwater, and 
marine systems. We summarize current strategies for identifying and prioritizing global biodiversity monitoring that could be utilized by Biodiversity Observation Networks (BONs) to drive capacity building efforts. Our goal is to identify capacity building activities which will ultimately allow data from various national monitoring programs, regional biodiversity observation networks (RBONs), and global NGOs to be combined into coherent datasets to assess the status and trends of biodiversity, and the drivers of biodiversity change, across the world (Schmeller et al. 2015).

\section{A capacity building framework in biodiversity monitoring}

Capacity building constitutes an integral part of the CBD and is featured in the original text of the convention as well as in the Aichi Biodiversity Targets under Strategic Goal E ('Enhance implementation through participatory planning, knowledge management, and capacity building; Böhm and Collen 2015). While not properly defined, the term as used in the CBD context - includes the training of, and knowledge exchange between, people and the strengthening of institutions (Korn et al. 2004). Therefore, capacity building includes wide-ranging activities, such as holding workshops, training courses, and conferences; creating and disseminating publications; facilitating data management and sharing; finding funding; and sourcing of technology to build the strength of research institutions, government organizations, and non-governmental organizations. Different capacity building activities are likely to reach different audiences and across different spatial scales. For example, some activities aim at distributing knowledge to large audiences (one-to-many flow of capacity) across large geographical scales (e.g., via dissemination of knowledge in literature through open access publishing, web-based learning, conferences), while others directly target (sometimes one-to-one) audiences in specific locations (e.g., through workshops, correspondence, and mentoring schemes; Böhm and Collen 2015). Here, we make 
use of this wide definition of capacity building and consider both institutional and people-based capacity building, including the management of Big Biodiversity Data (Hardisty and Roberts 2013; Hoffmann et al. 2014) and the mobilization of monetary resources to build new monitoring capacities in the most biodiversity-rich regions (Pereira et al. 2010).

There are six steps to implementing biodiversity monitoring: i) identifying monitoring questions and aims; (ii) identifying the key components, functions, and processes to monitor and the precision (e.g., sample size) required to answer the questions identified in step (i); (iii) identifying the most suitable monitoring methods for these elements, (iv), carrying out monitoring activities; (v) managing the resultant data; and (vi) interpreting monitoring data. Biodiversity Observation Networks (BONs) can be key players in driving forward all of these steps by identifying knowledge gaps and removing regional biases, identifying synergies across habitats, linking sampling approaches across spatial scales; ensuring data connectivity and coordination, and verifying policy relevance and application (Figure 1). Most new terrestrial monitoring programs established across the world and especially in developing regions in Asia, South America and Africa (Cui et al. 2014; Jürgens et al. 2012; Magnusson 2014; Yahara et al. 2014), monitor progress towards the objectives of the Strategic Plan for Biodiversity of the CBD (http://www.cbd.int/sp/targets/). Only with policy-relevant data, which are current, reliable, comparable among sites, and understandable (Schmeller et al. 2015), may international conventions and processes like the CBD and the Intergovernmental Platform for Biodiversity and Ecosystem Services (IPBES) succeed in producing a reliable trend analysis of global biodiversity (Schmeller and Bridgewater 2016; Vohland and Nadim 2015). 
Biodiversity monitoring data can differ in spatial and temporal coverage, effort of monitoring per site, involvement of experts and volunteers, and sampling frequency. Biodiversity data are generally collected through one of four schemes: (i) extensive monitoring programs, (ii) intensive monitoring programs, (iii) ecological field studies, and (iv) satellite remote sensing (Proença et al. in press). A robust and effective biodiversity monitoring program to fill global data gaps will include a combination of these and build capacity across a wide range of stakeholders (Figures 1 and 2). Below we review the capacity needs for each approach.

\section{Building capacity for extensive monitoring programs}

Extensive monitoring programs have high spatial coverage with relatively little effort expanded per monitoring site. They are generally run over long time periods and capture data on species populations, presence and absence, and community composition (Proença et al. (in press). Large extensive monitoring systems can require several thousand people to monitor selected species if the number of sites is high. The necessary knowledge levels to carry out the monitoring are relatively low, as programs are often aimed at common, charismatic, or conspicuous taxa (e.g. birds, butterflies; (Schmeller et al. 2012a; van Swaay et al. 2008). Therefore, capacity building for such programs may focus on activities aimed at building large networks of volunteers with basic skill levels (Schmeller et al. 2017).

Large-scale distribution of simple monitoring protocols, publications to aid species identification, and the involvement of relevant non-governmental organizations and citizen scientists (including utilization of traditional ecological knowledge) provide effective ways to maximize the success of extensive monitoring programs (Schmeller et al. 2009). 
Building capacity in participatory monitoring networks

Traditionally, local residents and indigenous people are the primary witnesses of biodiversity change, but are generally the least involved in current biodiversity monitoring programs, despite their imminent value (Díaz et al. 2015). These communities can share additional information on biodiversity change, as they often hold relevant traditional ecological or local knowledge drawing on personal experience which may have been handed down through many generations (Díaz et al. 2015). This information is especially important in remote areas where long-term, repeated monitoring is difficult to implement or has been implemented belatedly. Therefore, the involvement of volunteers and local communities in monitoring is key to maximizing sampling effort, by acquiring a broad picture of environmental change and biodiversity status (Engel and Voshell Jr 2002; Schmeller et al. 2012b; 2009). An additional benefit from participation of locals in biodiversity monitoring is the concomitant increase in environmental awareness, trust in the policy outputs supported by the collected observation data, and management through their involvement (Danielsen et al. 2003). Newly established BONs should therefore place particular importance on developing the capacity of community-based or volunteer-based monitoring efforts, while learning from previous experiences and ensuring these monitoring efforts are sustained into the future by being cost-effective and sustainable beyond the point where initial project funding stops (Danielsen et al. 2003).

Moreover, there are important synergies that come about when integrating different kinds of groups of people into coordinating monitoring systems or networks (Chandler et al. 2016). For example, the Brazilian Program for Biodiversity Research (PPBio) used a system based on regional hubs and the involvement of local people, with qualifications ranging from doctoral degrees to no formal education (Magnusson et al. 2013). Since its inception in 2004, it has successfully trained over 1000 local people 
through formal and informal courses (Magnusson et al. 2013). PPBio was created by the Brazilian Ministry of Science and Technology, but operates as a loose consortium of research organizations with activities in all Brazilian biomes. It involves activities in all aspects of biodiversity research, including monitoring, biological-collection maintenance and data availability. However, it is best known for the installation of spatially standardized field sites that follow the RAPELD system (Rapid Assessment in long-term ecological research sites; Magnusson et al. 2013; 2005). Local people trained in the RAPELD system in one area are in high demand for installation of infrastructure and training courses in other areas. They have deep traditional knowledge of local biological processes, as well as the newer demands resulting from the globalization of even the most remote areas.

Participatory monitoring networks (PMNs) or community-based networks are socially complex and their success or failure depends on cultural and historical elements that vary strongly between regions, communities and groups (Bell et al. 2008; Vandzinskaite et al. 2010). Therefore, networks developed in industrialized countries, which are often based on volunteer participation (Schmeller et al. 2009), may differ substantially from those in more resource-constrained countries, where involvement may often be driven by having a say in the management of local biodiversity. Thus, different strategies for motivating participants will need to be employed, taking local customs and culture into consideration, in order to promote the longevity of the monitoring program (Figure 3). These are crucial points and often lead to controversy about the effectiveness and advantages of PMNs (Danielsen et al. 2003; 2005; 2006; Schmeller et al. 2009; 2012b; Yoccoz et al. 2001; 2003). 
The role of new technology in extensive monitoring programs

Where the establishment of citizen science or PMNs is difficult, due to remoteness of a region or recurring costs of training or travel, new technology can play a key part in providing standardized methods for extensive monitoring of biodiversity. For example, by installing a network of camera traps in an area at certain spatial intervals, and sending photos via satellite to an office computer for data analysis, we can observe species living under environmental conditions difficult for human observers. Examples of such species include penguins (http://www.penguinlifelines.org/; Newbery and Southwell 2009), caribou (Rangifer tarandus), and ptarmigan (Lagopus spp.; Tape and Gustine 2014). Cameras may also be used in unmanned aerial vehicles (UAV), as used to investigate Antarctic moss beds (Lucieer et al. 2014). Important advances have been made in estimating densities and population sizes from camera trap data using Random Encounter Models and Non-Instantaneous Plot Sampling (Rowcliffe et al. $2008 ; 2011 ; 2012)$, and in integrating data derived from different monitoring techniques (Popescu et al. 2014). Current research and technological advances make data from camera traps highly suitable for robust long-term biodiversity monitoring of animals of sufficient size (usually mammals; e.g. Rich et al. 2014) and for indicator development (e.g. Wildlife Picture Index; Nichols 2010). Installment and maintenance of camera traps in the field may again rely on help from local communities, while the large quantities of photo imagery may also call for a large amount of enthusiastic volunteers ready to invest their time to analyze those images at their desks (Sheil et al. 2013) or via mobile apps and social media encouraging citizen science (e.g. InstantWild, Andrews 2013; Enjoy Moths, Lin et al. 2015).

Similarly, soundscapes, including anthrophony, geophony, and biophony, allow simultaneous monitoring of a number of species (e.g., amphibians, birds, and mammals, including marine mammals and birds) in remote areas. They may also allow 
monitoring of disturbance caused by human activities and natural disturbances (McWilliam 2016; Smith and Pijanowski 2014). Advances have been made in automatically analyzing soundscapes and also creating 3D sound profiles, via sound patch analyses and acoustic gap analyses (Eldridge et al. 2015; Pijanowski and Farina 2011; Pijanowski et al. 2011; https://www.recordtheearth.org/index.php). These advances render soundscaping highly usable for biodiversity monitoring to sample species that create typical sounds (singing of birds, croaking of amphibians, chirping of grasshoppers, etc.). Similarly, hydrophones can be used for monitoring marine species (Lammers et al. 2008; Nedelec et al. 2015; Wiggins and Hildebrand 2007). Rollout of standardized protocols for soundscaping and camera trapping across large regions can provide extensive monitoring based on recording the presence of species as well as population sizes and abundances; recently, this has been explored widely in the marine biome (Erbe et al. 2016; Merchant et al. 2016; Sánchez-Gendriz and Padovese 2016).

The development of machine olfaction systems, also termed artificial noses, and currently often used in industry and environmental monitoring (Bourgeois et al. 2003; Dickinson et al. 1998), may also have important potential for extensive biodiversity monitoring programs (Scott et al. 2006). Using such technology would allow the generation of a smellscape of the environment, and may help detect biomolecules, such as pheromones or other species-specific molecules (Raiteri et al. 2002). Indirect automated species monitoring would then be possible across large spatial scales. Artificial noses may also allow for the monitoring of ecosystems and their functioning, especially in cases where pollution may lead to disruption of natural smellscapes that might be important for intra- and interspecific interactions (Van Donk et al. 2016). Due to the interest of industry in automated olfaction systems, systems of analysis and data 
curation have already been developed (Scott et al. 2006) and derived systems for biodiversity monitoring may therefore be relatively easy to develop.

Whether to use technology to achieve biodiversity monitoring or PMNs depends on the objectives of the project (e.g. additional objectives of environmental education and locally-driven sustainable resource management suggest some form of PMNs, while simple biodiversity data collection in remote areas may suggest the use of specialized technologies) and project budget, as use of technology is constrained primarily by expenditure. Given the technology itself and the technicalities of resulting data analysis techniques, much higher technical skill levels are needed than for citizen sciencebased field monitoring, requiring input from the scientific community to transfer skills to their peers. However, on occasion, new technologies can be coupled with citizen science to achieve maximum outputs for monitoring. In France, new technologies have facilitated extensive bat monitoring by citizen scientists, because participants were motivated by the opportunity to use cutting-edge technology. Since no particular skills were needed in the field, this approach allowed anyone to participate (Penone et al. 2013). Generally, when developing new analysis methods, citizen scientists' involvement should be considered, e.g. to identifying relevant photos from camera trapping or patterns in sonograms or smellscapes, using e.g. Zooniverse (https://www.zooniverse.org/) as a blue print (Simpson et al. 2014).

\section{Building capacity for intensive monitoring programs}

Intensive monitoring programs invest in effort per site at the expense of geographic coverage, and are typically hypothesis-driven, aiming at monitoring ecological responses to environmental change (e.g., ecosystem functioning and species interactions; (Proença et al. in press). These have a low spatial coverage compared to extensive monitoring programs, but are important for scaling and interpolation when combined with extensive monitoring programs. The higher effort results from the aim to 
gather high resolution biodiversity data over long time periods at high sampling frequencies. Generally, high-resolution data for many invertebrate taxa are sparse across all realms, especially in the highly biodiverse tropics and subtropics and in freshwater habitats (Cardoso et al. 2011). While invertebrates are often not the focus of extensive, citizen science-driven monitoring programs, they may be monitored in intensive monitoring networks by recombining information collected by enthusiasts at their favorite sites, e.g. on spiders or cave biodiversity (Gollan et al. 2010).

Intensive monitoring programs rely on specialist capacity and skills, and may include capacity building aimed at professional development (e.g. mentoring schemes, workshops etc.). As monitoring effort needs to be maintained across many years or decades to yield precise, comparable data that allow the accurate measurement of impacts on organisms, communities, habitats, and ecosystems across time and space (Costello, et al., 2015; Schmeller et al., 2015), capacity building of well-trained data recorders with reliable taxonomic knowledge and survey skills is needed on the ground (Figure 3).

Intensive monitoring programs may use the same new technology as introduced for extensive monitoring programs. However, in intensive monitoring programs such technologies may be used in conjunction with additional field observations and at much higher spatial and temporal resolution (deployment), depending on the scientific questions asked. In addition, more costly approaches, such as environmental DNA (eDNA), are good means to complement field observations and to improve taxonomic, spatial and temporal coverage of intensive monitoring programs. Environmental DNA approaches offer the possibility of monitoring elusive and rare species and undetected invasive species, with the further advantage that sampling eDNA is non-invasive and can be applied to all realms (Bohmann et al. 2014; Foote et al. 2012; Thomsen et al. 
2012), potentially in a more cost-effective manner (Foote et al. 2012). First used to detect plant DNA in soil (Paget et al. 1998) and for large mammals (Martellini et al. 2005), much progress has been made in detecting even smaller DNA traces (Thomsen et al. 2012) and in analyzing large amounts of data (Lodge et al. 2012). The cost of analyses, especially next-generation techniques, is decreasing rapidly, and the range of questions that can be answered is increasing as quickly; this may allow the closing of taxonomic and spatial gaps. Therefore, it is worthwhile for scientists and trained experts (i.e. paraecologists and parataxonomists, see below) to collect material for genetic analyses; in certain environments, the involvement of citizen scientists for data collection may be possible (see freshwater biodiversity monitoring below), potentially paving the way for eDNA to become a standard technique in both intensive and extensive monitoring programs.

Most important in the setup of any monitoring systems is the establishment and effective use of an infrastructure across sites, and this is of particular importance in the case of intensive monitoring systems. Long-term ecological research networks (LTER) comprise monitoring sites where intensive monitoring programs are applied over long timescales. The global long-term ecological research network (iLTER) has made important advances in developing an e-infrastructure that unifies and harmonizes data from approximately 600 plots across terrestrial, freshwater and marine realms worldwide. At these plots long-term site-based ecological and socio-economic research and monitoring is conducted, providing invaluably rich biodiversity data at very high resolution (Haase et al. 2016). LTER-Europe has established the metadata documentation and retrieval system DEIMS (Drupal Ecological Information Management System; http://data.Iter-europe.net/deims/) that allows for information searches about sites, parameters, data sets, and people, and the interactive web tool ECOPAR (Parameters and Methods for Ecosystem Research \& Monitoring; 
http://www.ufz.de/ecopar) that facilitates the selection of indicators, parameters and standard methods (Haase et al. 2016). However, building further capacity in bioinformatics and e-infrastructures is needed to ensure that such networks can contribute to the understanding of global environmental changes and their impacts on ecosystem structures, processes and functions, and in turn help to tackle grand ecological and socio-economic challenges through focused long-term research (Haase et al. 2016).

Building capacity in intensive monitoring for freshwater systems Today's freshwater monitoring is hampered by low taxonomic resolution of freshwater species (Friberg et al. 2006). In the few nations that have made use of aquatic biodiversity monitoring (Liess and von der Ohe 2005; Schäfer et al. 2012) to inform freshwater policy (e.g. EU Water Framework Directive, U.S. Clean Water Act), the use of a coarse taxonomic level (family-level, e.g. South African Scoring System; (Dickens and Graham 2002) severely affects data quality. For example, several benthic invertebrate families consist of more than 100 species with often vastly different ecosystem requirements, ecological thresholds and indicative properties, making family-level resolution insufficient for detecting species-specific sensitivities to stressors (Lenat and Resh 2011).

Due to insufficient taxonomic knowledge, species-based freshwater monitoring programs are currently unrealistic in certain areas (e.g., least developed countries), so that monitoring programs at genus or family level may serve as a practical starting point. However, high resolution biodiversity data are urgently needed for the conservation of species, especially threatened and endemic species within global biodiversity hotspots (Darwall et al. 2011). Taxonomic training programs, together with funding for field monitoring and surveys, are required to address capacity shortfalls. 
Further, freshwater biodiversity data need to be coupled with the landscape context in which the freshwater habitats occur (Costa and Magnusson 2010; Magnusson 2014) and data availability for most regions is still poor, particularly in developing countries (Tonkin et al. 2016).

Recent progress in eDNA techniques (Deiner et al. 2015) and metagenomics may help to overcome some of these issues. As the eDNA approach is based on filtered water samples, sampling could be supported by trained citizen scientists. The resulting taxon list is at the (sub-) species level, allowing for more detailed assessments of freshwater ecosystems. In addition, recent advance in metagenomics allow the identification of all taxa of a benthic invertebrate sample (based on e.g. kick-sampling with a hand net) to species level, and much progress has been made in terms of quantifying such samples (Elbrecht and Leese 2015).

Building capacity in intensive marine biodiversity monitoring The establishment of intensive monitoring networks is particularly needed for the marine realm, since marine biodiversity monitoring is still lagging behind terrestrial monitoring programs (Duffy et al. 2013), mostly because marine research is expensive and logistically challenging. The frequent requirement for specialized technologies and equipment, such as oceanographic research vessels and submersibles, adds costs to data collection exceeding those typically experienced in terrestrial or freshwater systems. This limits the number of research organizations and projects with the capability to carry out biodiversity monitoring, and generally precludes the use of citizen scientists for in situ data collection in favor of intensive monitoring programs or ecological field studies. There are currently only a handful of volunteer-based monitoring programs for marine species: sea turtles (State of the World's Sea Turtles; SWOT; http://www.seaturtlestatus.org/); marine fish (the REEF Volunteer Fish Survey 
Project, www.reef.org; SeaSearch http://www.seasearch.org.uk/), cetaceans (the Australian National Whale and Dolphin Sightings and Strandings Database; https://data.marinemammals.gov.au/), and jellyfish (jellywatch, http://www.jellywatch.org/).

Professional networks and collaborations are largely responsible for disseminating data and building capacity in the field of marine monitoring (Figure 1). The ten-year global Census of Marine Life programme improved access to data on marine life, and identified unexplored regions and knowledge gaps (Costello et al. 2010, 2013a; 2013b, 2015, in press). Further global initiatives, such as the Global Coral Reef Monitoring Network (GCRMN; http://gcrmn.org/), and Kelp Ecosystems Ecology Network (KEEN; http://www.kelpecosystems.org/), have provided rigorous quantitative baselines through intensive monitoring (Costello et al. in press). They have compiled data to provide trends on taxa of interest, strengthened communication and reporting, and provided technical assistance between partner institutions. Nevertheless, there are still methodological issues to consider when developing marine biodiversity monitoring programs (Heslenfeld and Enserink 2012; Zampoukas et al. 2013). For example, in areas where it is difficult to provide adequate biodiversity monitoring coverage, intensive and extensive sampling regimes should be utilized in parallel, with multiple measures being employed at key sites (intensive research and monitoring) and simpler, cost-effective sampling across wider areas (extensive sampling); these efforts should be supplemented with modelling approaches to infer patterns of status, trends and the causal mechanisms of biodiversity change (Gill et al. 2011). Actual marine monitoring programs could be developed in close collaboration with different private industries, which maintain a large fleet of vessels and offshore rigs. If such a costefficient measure could be used by independent observers, more data on marine biodiversity could be collected (Martinez-Cedeira et al. 2003). 
Building capacity through the employment of paraecologists or parataxonomists In the terrestrial realm, local participatory programs, such as those discussed for extensive monitoring programs, have been extended to involve "paraecologists" or "parataxonomists" (Schmiedel et al. 2016). These are often specialists with good-toexcellent local knowledge, or members of the local community who have received special technical training in ecological or taxonomic survey techniques to provide more in-depth monitoring and to provide a link between researchers and the local community, for example. Thus, paraecologists and parataxonomists are more technically trained than citizen scientists (Basset et al. 2004). The involvement of local community members as paraecologists and parataxonomists helps to facilitate the communication between land-users and researchers and contributes to research activities and local development (www.paraecologist.org). Paraecologists and parataxonomists are involved in a number of activities relating to biodiversity monitoring, such as biodiversity assessment, DNA barcoding (Janzen and Hallwachs 2011), knowledge sharing, outreach activities, and climate-change adaptation. They work full-time in a professional research environment, either independently or in a team with academic and non-academic colleagues. This requires that they work in a meticulous, reliable, verifiable and well-documented manner. The skills that are required from paraecologists and parataxonomists cannot be taken for granted in rural environments, where formal employment and professional training are limited. The paraecologist or parataxonomist approach is thus one important approach in building local monitoring capacity, but respective programs inevitably require long-term funding and mentoring, on-the-job training and specialized training courses, and therefore generate higher per-person costs than for volunteer networks established for extensive monitoring programs. 
BIOTA Southern Africa, an example of intensive monitoring, actively involved members of local land-user communities who live in the immediate vicinity of Biodiversity Observatory sites (Jürgens et al. 2010; 2012; Schmiedel et al. 2010). Up to eight paraecologists were employed to support the biodiversity assessment and monitoring on the standardized observation sites in Namibia and South Africa from 2004 until 2010 (Schmiedel et al. 2010). The involvement of paraecologists helped both the scientists and local communities; scientists were better able to understand the land users' perspective of the natural and social environment, as well as the constraints, challenges and incentives for their land-management decisions, and paraecologists were advantageous for researchers, particularly when conducting research in a new environment and on data-deficient, poorly studied species. The paraecologists became instrumental in knowledge exchange between scientists and land users, helping to expand the local knowledge base by referring to observational data, which aided local management decisions. The paraecologist program in BIOTA also resulted in important awareness-raising and environmental education among local communities, thus contributing towards the empowerment of the land-user communities. An added benefit of paraecologist training can be to increase identification skills of the trainees from wellmonitored species groups such as birds and butterflies to lesser studied groups such as other insect groups, spiders or molluscs, allowing for better taxonomic coverage of the monitoring program.

\section{Building capacity for ecological field studies}

Ecological field studies are defined as experimental or observational studies located outdoors (Martin et al. 2012). They are not part of monitoring programs, and although the methods may be similar to the ones used in intensive monitoring programs, the aims are often more diverse, focusing on delivering answers to specific ecological questions. They are distinct from monitoring programs due to their usually local scale 
and their tendency to be carried out over shorter time frames. Methods of both extensive and intensive monitoring programs may be applied in ecological studies, but ecological studies aim to answer a more diverse array of ecological questions than intensive programs and therefore may employ more complex field protocols and experimental setups to answer questions relating biodiversity to ecosystem structure and function, as well as to drivers and pressures (Haase et al. 2016).

Due to their answering specific ecological questions, ecological field studies are largely carried out independently and cover a wide variety of ecosystem types, plot sizes, infrastructure, and instrumentation, with individual sites measuring a wide range of abiotic and biotic parameters according to site-specific protocols. As such local studies often yield important data on ecological processes and specific impacts of different drivers and pressures; these data can be compiled and used as monitoring data and can be combined with data from extensive as well as intensive monitoring programs to understand better the observed large scale patterns of species occurrence and abundance. Mobilizing such data has been considered an important and urgently needed advance in biodiversity monitoring (Hoffmann et al. 2014). Challenges occur due to current data policies. Data would need to be processed, structured, and unified to enhance data mobilization and interoperability and to allow data from different ecological studies to contribute to a larger-scale understanding of biodiversity patterns (Egloff et al. 2016). In fact, ecological studies can be included in global scale indicators, much like extensive and intensive monitoring programs, as exemplified by the use of vertebrate population time series data derived from different monitoring programs, including ecological field studies, for the Living Planet Index (Collen et al. 2009). Capacity building in ecological field studies should therefore focus on finding and developing solutions in biodiversity informatics and engineering technologies, to allow for systematic information management (Koureas et al. 2016). Existing e- 
infrastructures, such as the Global Biodiversity Information Facility (GBIF), already offer data standards and publishing tools for mobilizing and integrating species locality data - in particular the Darwin Core vocabulary for documenting occurrences of species in time and space (http://rs.tdwg.org/dwc/terms/simple/index.htm). More recently, these standards have been extended to support integration of a richer set of data elements common to a wide variety of ecological studies. This has enabled GBIF to move beyond cataloguing only species' presence records to also handle "samplingevent datasets" (http://www.gbif.org/publishing-data/summary\#datasetclasses) which report sets of species recorded in a single sample, including links to metadata on sampling methods and measure of relative abundance of species sampled. These processes and infrastructure will enable the integration and simultaneous discovery of the widest possible range of ecological and other species-based data to support largescale biodiversity monitoring, and will assist with addressing the fragmented landscape of ecological studies to maximize impact on our understanding of global and regional biodiversity patterns (Koureas et al. 2016).

\section{Building capacity in remote sensing for biodiversity monitoring}

Earth observations are an important information source for biodiversity monitoring and conservation applications, providing continuous, standardized data on many aspects of ecosystem distribution, structure, function, composition and dynamics (Duro et al. 2007; Kachelriess et al. 2014; Pettorelli et al. 2012; 2014a; 2016). They can provide information on numbers of individuals, species distributions or community composition. Numerous studies have highlighted the potential key role of satellite data in macroecology, plant ecology, animal population dynamics, habitat-selection and habitat-use studies, movement ecology, and paleoecology (Pettorelli et al. 2011). For example, remote sensing can help track changes in species diversity of plants (specifically alpha diversity; Rocchini et al. 2016) by providing repeated measures over 
large, often global scales. On a species level, remotely-sensed satellite imagery has been used to monitor emperor penguins (Aptenodytes forsteri; Barber-Meyer et al. 2007), Weddell seals (Leptonychotes weddellii; LaRue et al. 2011) and polar bears (Ursus maritimus; Stapleton et al. 2014) and offers many more opportunities for monitoring plant species (He et al. 2011). As an example of the potential of this technology to link local studies with global assessments, remotely-sensed satellite imagery of the seven known Ross Sea emperor penguin colonies were collected (Barber-Meyer et al. 2008; 2007), and images classified to distinguish between areas containing penguins, only guano, or bare ice. Other researchers then refined and expanded the technique to identify new emperor penguin-colony locations (Fretwell and Trathan 2009) and to generate a global, synoptic survey of penguin species from space (Fretwell et al. 2012; Lynch and LaRue 2014).

Remote sensing is likely to improve our ability to predict species distributions over time (He et al. 2015), thus enabling the filling of data gaps for remote or logistically difficult regions, and to put drivers of decline into the context of species population parameters (e.g. range changes Pettorelli et al. 2014a). A key feature of satellite imagery is that it can be applied retrospectively across wide regions, providing a unique opportunity to reanalyze historic data and make use of previously unavailable information, thus allowing analysis of trends over time (e.g. forest loss; Hansen et al. 2013). New algorithms to analyze remotely sensed imagery are allowing more sophisticated processing workflows and a wider application of remote sensing in monitoring of terrestrial species (Stepanian et al. 2014). Because remote-sensing technology is logistically less intense, is developing rapidly and there is increased accessibility of data, greater temporal and spectral coverage is expected in the future, with many more biological-monitoring applications likely to be forthcoming. However, the benefits of remote-sensing technology often remain inaccessible to the communities that need 
them the most (Turner 2013). Although a variety of products based on earthobservation data are now freely available, a significant proportion is not. More importantly, training in the technical knowledge necessary to make use of remote sensing data is hampering the accessibility of remote sensing data (Turner et al. 2015). This includes high equipment costs, since remote sensing techniques require access to high-end computer and memory resources, software packages for data analysis and display, and access to the relevant expertise for processing and analyzing large datasets (Kachelriess et al. 2014). Although open access solutions are on the rise (e.g., packages for R, QGIS and GRASS), the frequent lack of clear documentation, the partial absence of a graphical user interface, and the need to be technically versed at the interface of the two disciplines (Pettorelli et al. 2014b), mean that remote sensing is currently aimed mostly at highly trained specialists. However, some user-friendly applications are in or have been developed that will lower the threshold for the access and application of remotely sensed information (e.g. TerraLook; http://terralook.sourceforge.net/).

Considering the power of remote sensing to provide information on species and ecosystem processes over global scales, even given the potential cost and technical know-how required, building capacity in this growing area of research and monitoring is vital in order to fill current gaps in the coverage of biodiversity monitoring. Building this capacity needs to address data-access issues, methodological collaborations (Pettorelli et al. 2014a; Pettorelli et al. 2016 - in press), institutional capacity and individual training needs. In that regard, new approaches may also need to be developed, allowing participation of volunteers in image analysis, such as Zooniverse (https://www.zooniverse.org/; Simpson et al. 2014). 
In terms of data access, collaborations with agencies holding remotely-sensed data need to be improved to make these data freely available to biodiversity-monitoring projects (i.e. taxpayer-funded satellite images need to be made available free of charge where possible; Turner 2013). In many cases, initiating collaborations between the data providers (the remote sensing community) and biodiversity-monitoring researchers is likely to provide an incentive for data sharing, as well as the technical know-how to develop new algorithms and provide data validation and calibration services to help with specific monitoring needs (Pettorelli et al. 2016 - in press). In terms of institutional and individual capacity, access to training opportunities is vital, focusing on the use of free analysis tools, especially in developing countries (Asner et al. 2011; Schietti et al. 2014). Dissemination of and training in remote-sensing techniques through workshops (specifically aimed at ecologists and conservation practitioners), conferences, open access journals (e.g., RSEC; (Pettorelli et al. 2014a); Nature Conservation; (Henle et al. 2012) is important for building a new generation of scientists able to carry out integrated, multi-disciplinary approaches (Pettorelli et al. 2014a). Given the up-and-coming nature of remote sensing for ecology and biodiversity monitoring, the development of user-friendly, intuitive, and centralized data portals to enhance communication and exchange of experiences about remote-sensing products is key.

Overarching recommendations for capacity building in biodiversity monitoring Key recommendations for biodiversity monitoring (see also Figures 1 and 3 ) include that:

1. A consistent monitoring program should comprise at least three elements:

i. surveillance or hypothesis-driven monitoring covering different habitat types, with sampling carried out in regular intervals as recommended in the European Nature Directives to build a baseline database; 
ii. an operational and periodic evaluation program where deficits in the network are detected and addressed;

iii. high-resolution monitoring sites in biodiversity hotspots, where monitoring should be carried out even more frequently.

2. When selecting new monitoring sites, several factors need to be considered:

i. availability of reference sites or sites in natural condition reflecting the different habitat types of the region being investigated;

ii. determination of the types and impacts of anthropogenic activity to be monitored, which will affect site selection (e.g. along a gradient of pollution);

iii. practicality of supplementing biological measurements with physical measurements (e.g. temperature, turbidity, etc.) in order to determine the mechanisms influencing biodiversity state and trends.

3. Consistent monitoring should be organized by BONs or similar networks:

i. placement of monitoring sites, scaling of monitoring efforts, and combination of monitoring data may be overseen by a BON or similar network

ii. organization of capacity building for citizen scientists, paraecologists or parataxonomists in taxonomic identification skills and knowledge of actual ecological monitoring in the field by trained experts may be developed by BONs or similar networks.

iii. BONs or similar networks should provide repeated gap and power analyses to continuously improve the biodiversity monitoring agenda (Figure 1).

4. To increase capacity, biodiversity monitoring need to tap into different sectors of society including the private sector and citizen scientists (Figure 3), as in the following examples:

Integrating monitoring protocols for Essential Biodiversity Variables (EBVs; Proenca et al. in press; Pereira et al. 2017) with monitoring needs for Environmental Impact 
Assessments may allow more data to become available through private sector engagement. Citizen science approaches have already been established through the tourism industry (e.g. presence of lichen species on the Antarctic peninsula to ground truth satellite remote sensing data; Casanovas et al. 2013). Expanding such costeffective collaborations is paramount, as is the need to couple these collaborations with extensive environmental education to disseminate information on the state of nature to a wider audience. Additionally, new data sources for biodiversity monitoring may come from social media using natural language processing (Lin et al. 2015), and can, where social media or deposited photographs are geo-referenced, improve spatial data availability, thus increasing the predictive power of species distribution and other modeling approaches.

Effective monitoring programs are needed in countries with high proportions of global biodiversity, particularly in the tropics. Such monitoring programs should include the implementation of biodiversity observatories for long-term monitoring, and especially for freshwater and marine monitoring. Building capacity for biodiversity monitoring in biodiversity-rich countries relies on the establishment of technical expertise and the establishment and strengthening of institutions for long-term monitoring. Crossorganizational partnerships between developed and developing countries are likely to be a primary driver. Additionally, the involvement of citizen scientists, communities and paraecologists or parataxonomists may provide possible solutions, specifically as the acquisition of knowledge is a major motivational factor. Formal and recurring training is therefore not only important for technical staff, but also for citizen science and community engagement, requiring continued adequate funding and mentoring of training schemes. Similarly, any scheme intended to engage with local paraecologists or parataxonomists and communities requires understanding of cultural differences and language limitations to positively influence levels of participation. These challenges, 
including budget requirements, mentorship, personal commitment, long-term perspectives, learning and working opportunities, cultural differences, and community envy, can be significant and should be dealt with adequately (Schmiedel et al. 2016). 5. Finally, several non-exclusive approaches may help to focus the limited resources available for initial capacity building in biodiversity monitoring:

i. Focus on target taxa, organisms and variables that are necessary to answer specific questions set by global biodiversity indicators (Biodiversity Indicator Partnership http://www.bipindicators.net/) (Geijzendorffer et al. 2016; Mace and Baillie 2007; Tittensor et al. 2014).

ii. Use the theory-driven EBV concept to detect information needs. EBVs hold the potential to streamline monitoring efforts for key data types, to standardize indicator computations and to identify existing information gaps with regard to temporal, spatial and taxonomic coverage (Geijzendorffer et al. 2016; Pereira et al. 2013).

iii. Identify Key Biodiversity Areas (KBAs). KBAs provide a highly structured approach, led by the IUCN (Eken et al. 2004), to identify sites of global importance for biodiversity conservation. Standardizing monitoring efforts across these areas could provide a basis of a truly global extensive (or even intensive, through participation of local research organizations) monitoring scheme (Anderson 2002; van Swaay and Warren 2003; Darwall et al. 2011).

iv. Local and topical priorities relevant to the needs of key biodiversity policy instruments, particularly in terms of reporting by the Contracting Parties, to achieve maximum impact and sustainability through support from national governments (Henle et al. 2013). Such an emphasis on topical priorities (e.g., species or habitats of special concern) can help determine where to focus initial capacity building; these efforts can then be complemented by other local, 
national and regional monitoring activities, following from the determination of national conservation responsibilities for species and habitats (Schmeller et al. 2008a; 2014; 2008b; 2012c).

\section{Conclusions}

Monitoring provides the data to document the status and trends of biodiversity, to inform conservation policy and to evaluate the effectiveness of existing regulations and policies. The challenges in building sufficient capacity in the field of biodiversity monitoring are different and manifold, depending on the monitoring system, ecosystem and taxa in question. In areas where it is difficult to provide adequate biodiversitymonitoring coverage, a multi-pronged approach with different monitoring programs should be implemented (e.g. intensive and extensive-sampling regimes, and earth observations), including the necessary capacity building activities. Here, multiple measures may be employed at key sites (intensive research and monitoring) and simpler, cost-effective sampling across wider areas (extensive sampling), with modeling approaches to infer patterns of status, trends and the causal mechanisms of biodiversity change (Gill et al., 2011). Integration of the different sampling regimes and resulting data should be overseen by BONs to ensure most efficient data use.

It is important to extend and harmonize existing networks, bringing players from novel sectors of society (e.g. private industries in marine system monitoring) to increase data collection opportunities, while developing statistical techniques to address any caveats such new approaches might bring. Taxonomic training is particularly important in the marine and freshwater realm, so that species- or genus-level monitoring can improve existing family-level biodiversity monitoring. In terrestrial monitoring, motivated citizens may help to collect biodiversity data across extensive (citizen science) and intensive 
monitoring systems (paraecologists, parataxonomists). Expanding involvement of local communities and the general public would increase the cost efficiency of monitoring.

New technologies can greatly enhance traditional field monitoring. Technologies may range from installing sound recorders, olfaction systems, or camera traps to the storage and analysis of Big Biodiversity Data. Two technologies are particularly promising; environmental DNA and satellite remote sensing. The use of eDNA will allow the detection of elusive species and determine the diversity at a given site (e.g. in intensive/extensive monitoring networks), while remote sensing can help to monitor populations of large characteristic species and provide data on changes in ecosystem structure and function. Where it seems unlikely that sufficient monitoring effort can be achieved in situ, and where satellite or remotely sensed data may provide a more costeffective way of monitoring large areas of inaccessible habitat (Degraer et al. 2008; Phinn et al. 2008; Wabnitz et al. 2008), capacity building needs to increase technical and data-storage capabilities for remote-sensing studies. Incorporating such techniques into monitoring protocols and biodiversity indicators provides valuable tools in monitoring large and remote ecosystems, such as marine ecosystems (Secades et al. 2014). As with all new technologies, more research is needed to validate and calibrate the methods, as well as to build technical know-how across global networks.

To date, many tropical and subtropical countries with limited resources are lagging behind with monitoring biodiversity, despite their species-rich fauna and flora. The scientific community of nations with more experience in monitoring programs should assist with the selection of appropriate monitoring sites, with overcoming taxonomic challenges, and in devising monitoring programs in species-rich environments, through technology transfer as stated in the CBD and Aichi Targets (Böhm and Collen 2015). However, it is imperative that such technical support is done in response to the clearly 
articulated needs and interests of those countries (e.g. supporting their sub-national and national reporting requirements on biodiversity conservation). Separate from technological advances, the management aspect of biodiversity monitoring needs to keep pace and consider the human dimension (Figure 3).

More rapid sharing and transfer of state-of-the-art tools and approaches for establishing and maintaining biodiversity monitoring systems is needed. Too often, multiple organizations are developing their own biodiversity-data management systems, thereby creating redundancies and non-standardized structures that limit interoperability of data (Schmeller et al. 2015). GEO BON's development of BON in a Box is a solution to this issue as it provides a means for rapid sharing and discoverability of the latest and best tools in use for biodiversity data collection, management and analysis.

Data currently unavailable and unexploited must be evaluated, published and converted to an electronic shared format, and potential information gaps need to be identified. Bio-informaticians, ecologists and other stakeholders must interact to find the most suitable process to allow more effective decision-making and better implementation of quantitative procedures that form the basis of modern ecology (Benedetti-Cecchi et al. 2003).

Here, we advocate that appropriate resourcing is needed to support the development of new biodiversity monitoring programs as well as the expansion or maintenance of existing ones, to close gaps in biodiversity data collection and deliver information that facilitates better conservation decisions, to link together existing and planned observation systems around the world, and to promote common technical standards. 


\section{References}

Anderson S (2002) Identifying Important Plant Areas: A Site Selection Manual for Europe, and a basis for developing guidelines for other regions of the world. A Site Selection Manual for Europe, and a basis for developing guidelines for other regions of the world Plantlife International, London

Andrews C (2013) Zoos of the future [Design Zoos] Engineering \& Technology 8:68-71

Asner GP et al. (2011) Taxonomy and remote sensing of leaf mass per area (LMA) in humid tropical forests Ecological Applications 21:85-98

Barber-Meyer S, Kooyman G, Ponganis P (2008) Trends in western Ross Sea emperor penguin chick abundances and their relationships to climate Antarctic Science 20:3-11

Barber-Meyer SM, Kooyman GL, Ponganis PJ (2007) Estimating the relative abundance of emperor penguins at inaccessible colonies using satellite imagery Polar Biology 30:1565-1570

Basset Y, Novotny V, Miller SE, Weiblen GD, Missa O, Stewart AJ (2004) Conservation and biological monitoring of tropical forests: the role of parataxonomists Journal of Applied Ecology 41:163-174

Bell S et al. (2008) What counts? Volunteers and their organisations in the recording and monitoring of biodiversity Biodiversity and Conservation 17:3443-3454

Benedetti-Cecchi L, Airoldi L, Fraschetti S, Terlizzi A (2003) Experimental methods for the assessment of anthropogenic impact on assemblages and coastal marine environments Biologia marina mediterranea 10

Böhm M, Collen B (2015) Toward equality of biodiversity knowledge through technology transfer Conservation Biology 29:1290-1302

Bohmann K et al. (2014) Environmental DNA for wildlife biology and biodiversity monitoring Trends in Ecology \& Evolution 29:358-367

Bourgeois W, Romain A-C, Nicolas J, Stuetz RM (2003) The use of sensor arrays for environmental monitoring: interests and limitations Journal of Environmental Monitoring 5:852-860 doi:10.1039/B307905H

Butchart SH et al. (2010) Global biodiversity: indicators of recent declines Science 328:1164-1168

Cardoso P, Erwin TL, Borges PA, New TR (2011) The seven impediments in invertebrate conservation and how to overcome them Biological Conservation 144:2647-2655

Casanovas P, Lynch HJ, Fagan WF (2013) Multi-scale patterns of moss and lichen richness on the Antarctic Peninsula Ecography 36:209-219

Collen BEN, Loh J, Whitmee S, McRae L, Amin R, Baillie JEM (2009) Monitoring Change in Vertebrate Abundance: the Living Planet Index Conservation Biology 23:317-327 doi:10.1111/j.1523-1739.2008.01117.x

Costa FRC, Magnusson WE (2010) The need for large-scale, integrated studies of biodiversity - the experience of the Program for Biodiversity Research in Brazilian Amazonia Natureza \& Conservação 8:3-12

Costello $\mathrm{M}$ et al. (in press) Methods for the study of marine biodiversity. In: Scholes RJ, Walters S (eds) GEO Handbook on Biodiversity Observation Networks. Springer,

Costello MJ et al. (2013a) Strategies for the sustainability of online open-access biodiversity databases Biological Conservation 173:155-165

Costello MJ et al. (2015) Organizing, supporting and linking the world marine biodiversity research community Journal of the Marine Biological Association of the United Kingdom 95:431-433 
Costello MJ et al. (2013b) Global coordination and standardisation in marine biodiversity through the World Register of Marine Species (WoRMS) and related databases Plos One 8:e51629

Costello MJ, Coll M, Danovaro R, Halpin P, Ojaveer H, Miloslavich P (2010) A Census of Marine Biodiversity Knowledge, Resources, and Future Challenges Plos One 5:e12110

Cui P et al. (2014) Status of Wintering Waterbirds at Selected Locations in China Waterbirds 37:402-409

Danielsen F, Burgess ND, Balmford A (2005) Monitoring matters: examining the potential of locally-based approaches Biodiversity and Conservation 14:25072542

Danielsen F et al. (2006) Monitoring matters: evaluating locally-based biodiversity monitoring in developing countries Oryx 40:14-15

Danielsen F, Mendoza MM, Alviola P, Balete DS, Enghoff M, Poulsen MK, Jensen AE (2003) Biodiversity monitoring in developing countries: what are we trying to achieve? Oryx 37:407-409

Darwall WR et al. (2011) Implications of bias in conservation research and investment for freshwater species Conservation Letters 4:474-482

Degraer S et al. (2008) Very-high resolution side-scan sonar mapping of biogenic reefs of the tube-worm Lanice conchilega Remote Sensing of Environment 112:33233328 doi:10.1016/j.rse.2007.12.012

Deiner K, Walser J-C, Mächler E, Altermatt F (2015) Choice of capture and extraction methods affect detection of freshwater biodiversity from environmental DNA Biological Conservation 183:53-63

Díaz S et al. (2015) The IPBES Conceptual Framework-connecting nature and people Current Opinion in Environmental Sustainability 14:1-16

Dickens CW, Graham P (2002) The South African Scoring System (SASS) version 5 rapid bioassessment method for rivers African Journal of Aquatic Science 27:110

Dickinson TA, White J, Kauer JS, Walt DR (1998) Current trends in 'artificial-nose' technology Trends in Biotechnology 16:250-258 doi:http://dx.doi.org/10.1016/S0167-7799(98)01185-8

Duffy JE, Amaral-Zettler LA, Fautin DG, Paulay G, Rynearson TA, Sosik HM, Stachowicz JJ (2013) Envisioning a marine biodiversity observation network BioScience 63:350-361

Duro DC, Coops NC, Wulder MA, Han T (2007) Development of a large area biodiversity monitoring system driven by remote sensing Progress in Physical Geography 31:235-260

Egloff W, Agosti D, Patterson D, Hoffmann A, Mietchen D, Kishor P, Penev L (2016) Data Policy Recommendations for Biodiversity Data. EU BON Project Report Research Ideas and Outcomes 2:e8458

Eken $\mathrm{G}$ et al. (2004) Key biodiversity areas as site conservation targets BioScience 54:1110-1118

Elbrecht $\mathrm{V}$, Leese $\mathrm{F}$ Testing primer bias and biomass-sequence relationships in metabarcoding: implications for monitoring of freshwater invertebrate communities. In: GENOME, 2015. vol 5. CANADIAN SCIENCE PUBLISHING, NRC RESEARCH PRESS 65 AURIGA DR, SUITE 203, OTTAWA, ON K2E 7W6, CANADA, pp 215-215

Eldridge AC, Casey M, Moscoso P, Peck M (2015) A new direction for Soundscape Ecology? Toward the extraction and evaluation of ecologically-meaningful soundscape objects using sparse coding methods. PeerJ PrePrints, 
Engel SR, Voshell Jr JR (2002) Volunteer Biological Monitoring: Can It Accurately Assess the Ecological Condition of Streams? American Entomologist 48:164177

Erbe C, McCauley R, Gavrilov A (2016) Characterizing Marine Soundscapes. In: The Effects of Noise on Aquatic Life II. Springer, pp 265-271

Foote AD et al. (2012) Investigating the potential use of environmental DNA (eDNA) for genetic monitoring of marine mammals Plos One 7:e41781

Fretwell PT et al. (2012) An emperor penguin population estimate: the first global, synoptic survey of a species from space Plos One 7:e33751

Fretwell PT, Trathan PN (2009) Penguins from space: faecal stains reveal the location of emperor penguin colonies Global Ecology and Biogeography 18:543-552

Friberg N, Sandin L, Furse MT, Larsen SE, Clarke RT, Haase P (2006) Comparison of macroinvertebrate sampling methods in Europe Hydrobiologia 566:365-378

Geijzendorffer IR et al. (2016) Bridging the gap between biodiversity data and policy reporting needs: An Essential Biodiversity Variables perspective Journal of Applied Ecology in press

Gill $M$ et al. (2011) Arctic marine biodiversity monitoring plan

Gollan JR, Smith HM, Bulbert M, Donnelly AP, Wilkie L (2010) Using spider web types as a substitute for assessing web-building spider biodiversity and the success of habitat restoration Biodiversity and conservation 19:3141-3155

Haase P, Frenzel M, Klotz S, Musche M, Stoll S (2016) The long-term ecological research (LTER) network: Relevance, current status, future perspective and examples from marine, freshwater and terrestrial long-term observation Ecological Indicators:1-3

Hansen MC et al. (2013) High-resolution global maps of 21st-century forest cover change science 342:850-853

Hardisty A, Roberts D (2013) A decadal view of biodiversity informatics: challenges and priorities BMC Ecology 13:16

He KS et al. (2015) Will remote sensing shape the next generation of species distribution models? Remote Sensing in Ecology and Conservation 1:4-18

He KS, Rocchini D, Neteler M, Nagendra H (2011) Benefits of hyperspectral remote sensing for tracking plant invasions Diversity and Distributions 17:381-392

Henle K, Bauch B, Auliya M, Külvik M, Pe'er G, Schmeller DS, Framstad E (2013) Priorities for biodiversity monitoring in Europe: A review of supranational policies and a novel scheme for integrative prioritization Ecological Indicators 33:5-18 doi:http://dx.doi.org/10.1016/j.ecolind.2013.03.028

Henle K et al. (2012) Nature Conservation - a new dimension in Open Access publishing bridging science and application Nature Conservation 1:1-10

Heslenfeld P, Enserink E (2012) OSPAR Ecological Quality Objectives : the utility of health indicators for the North Sea ICES Journal of Marine Science:1392-1397

Hoffmann A et al. (2014) Improved access to integrated biodiversity data for science, practice, and policy-the European Biodiversity Observation Network (EU BON) Nature Conservation 6:49-65

Janzen DH, Hallwachs W (2011) Joining inventory by parataxonomists with DNA barcoding of a large complex tropical conserved wildland in northwestern Costa Rica Plos One 6:e18123

Jürgens N, Hoffman MT, Schmiedel U (2010) Biodiversity in Southern Africa: Patterns at local scale: the BIOTA Observatories. Klaus Hess,

Jürgens N et al. (2012) The BIOTA Biodiversity Observatories in Africa - a standardized framework for large-scale environmental monitoring Environmental Monitoring and Assessment 184:655-678 
Kachelriess D, Wegmann M, Gollock M, Pettorelli N (2014) The application of remote sensing for marine protected area management Ecological Indicators 36:169177

Korn H, Schliep R, Epple C (2004) Report of the International Workshop "CapacityBuilding for Biodiversity in Central and Eastern Europe". Bonn,

Koureas D et al. (2016) Unifying European Biodiversity Informatics (BioUnify) Research Ideas and Outcomes 2:e7787

Lammers MO, Brainard RE, Au WW, Mooney TA, Wong KB (2008) An ecological acoustic recorder (EAR) for long-term monitoring of biological and anthropogenic sounds on coral reefs and other marine habitats The Journal of the Acoustical Society of America 123:1720

LaRue MA et al. (2011) Satellite imagery can be used to detect variation in abundance of Weddell seals (Leptonychotes weddellii) in Erebus Bay, Antarctica Polar Biology 34:1727-1737

Lenat DR, Resh VH (2011) Taxonomy and stream ecologyâ€"the benefits of genusand species-level identifications

Liess M, von der Ohe PC (2005) Analyzing effects of pesticides on invertebrate communities in streams Environmental Toxicology and Chemistry 24:954-965 doi:10.1897/03-652.1

Lin Y-P, Deng D-P, Lin W-C, Lemmens R, Crossman ND, Henle K, Schmeller DS (2015) Uncertainty analysis of crowd-sourced and professionally collected field data used in species distribution models of Taiwanese Moths Biological Conservation 181:102-110

Lodge DM et al. (2012) Conservation in a cup of water: estimating biodiversity and population abundance from environmental DNA Molecular Ecology 21:25552558 doi:10.1111/j.1365-294X.2012.05600.x

Loh J, Green RE, Ricketts T, Lamoreux J, Jenkins M, Kapos V, Randers J (2005) The Living Planet Index: using species population time series to track trends in biodiversity Philosophical Transactions of the Royal Society of London Series B-Biological Sciences 360:289-295

Lotze HK, Worm B (2009) Historical baselines for large marine animals Trends in Ecology \& Evolution 24:254-262

Lucieer A, Turner D, King DH, Robinson SA (2014) Using an Unmanned Aerial Vehicle (UAV) to capture micro-topography of Antarctic moss beds International Journal of Applied Earth Observation and Geoinformation 27:53-62

Lynch H, LaRue M (2014) First global census of the Adélie Penguin The Auk 131:457466

Mace GM, Baillie JE (2007) The 2010 biodiversity indicators: challenges for science and policy Conservation Biology 21:1406-1413

Magnusson W et al. (2013) Biodiversity and integrated environmental monitoring. Attema, Sao Paulo, Brazil

Magnusson WE (2014) Uncertainty and the design of in-situ biodiversity-monitoring programs Nature Conservation 8:77-94

Magnusson WE, Lima AP, Luizão R, Luizão F, Costa FR, CAStllHO CVd, Kinupp V (2005) RAPELD: a modification of the Gentry method for biodiversity surveys in long-term ecological research sites Biota neotropica 5:19-24

Marsh DM, Trenham PC (2008) Current Trends in Plant and Animal Population Monitoring Conservation Biology 22:647 - 655 doi:doi:10.1111/j.15231739.2008.00927.x

Martellini A, Payment P, Villemur R (2005) Use of eukaryotic mitochondrial DNA to differentiate human, bovine, porcine and ovine sources in fecally contaminated surface water Water Research 39:541-548 doi:10.1016/j.watres.2004.11.012 
Martin LJ, Blossey B, Ellis E (2012) Mapping where ecologists work: biases in the global distribution of terrestrial ecological observations Frontiers in Ecology and the Environment 10:195-201 doi:10.1890/110154

Martinez-Cedeira J et al. (2003) Avistamientos de cetáceos desde barcos de pesca en aguas de Galicia Galemys: Boletín SECEM:103-113

McRae L, Collen B, Deinet S, Hill P, Loh J, Baillie J, Price V (2012) The Living Planet Index. WWF International, Gland, Switzerland

McRae L, Deinet S, Freeman R (2016) The diversity weighted Living Planet Index: controlling for taxonomic bias in a global biodiversity index PeerJ Preprints 4:e2214v2211

McWilliam J (2016) Spatial Patterns of Inshore Marine Soundscapes. In: The Effects of Noise on Aquatic Life II. Springer, pp 697-703

Merchant ND, Pirotta E, Barton TR, Thompson PM (2016) Soundscape and Noise Exposure Monitoring in a Marine Protected Area Using Shipping Data and Time-Lapse Footage. In: The Effects of Noise on Aquatic Life II. Springer, pp 705-712

Mora C, Tittensor DP, Myers Ra (2008) The completeness of taxonomic inventories for describing the global diversity and distribution of marine fishes Proc $R$ Soc Lond, B 275:149-155 doi:10.1098/rspb.2007.1315

Nedelec SL, Simpson SD, Holderied M, Radford AN, Lecellier G, Radford C, Lecchini D (2015) Soundscapes and living communities in coral reefs: temporal and spatial variation Marine Ecology Progress Series 525:125-135

Newbery KB, Southwell C (2009) An automated camera system for remote monitoring in polar environments Cold Regions Science and Technology 55:47-51

Nichols J (2010) The wildlife picture index, monitoring and conservation Animal Conservation 13:344-346

Paget E, Lebrun M, Freyssinet G, Simonet P (1998) The fate of recombinant plant DNA in soil European Journal of Soil Biology 34:81-88 doi:10.1016/s11645563(99)90005-5

Penone C, Le Viol I, Pellissier V, Julien J-F, Bas Y, Kerbiriou C (2013) Use of LargeScale Acoustic Monitoring to Assess Anthropogenic Pressures on Orthoptera Communities Conservation Biology 27:979-987 doi:10.1111/cobi.12083

Pereira HM et al. (2010) Global biodiversity monitoring Frontiers in Ecology and the Environment 8:459-460

Pereira HM et al. (2013) Essential biodiversity variables Science 339:277-278

Pereira HM et al. (2017) Monitoring Essential Biodiversity Variables at the Species Level. In: Walters M, Scholes RJ (eds) The GEO Handbook on Biodiversity Observation Networks. Springer Nature, Cham, Switzerland, pp 79-105. doi:10.1007/978-3-319-27288-7_4

Pettorelli N, Chauvenet AnL, Duffy JP, Cornforth WA, Meillere Ae, Baillie JE (2012) Tracking the effect of climate change on ecosystem functioning using protected areas: Africa as a case study Ecological Indicators 20:269-276

Pettorelli N, Laurance WF, O'Brien TG, Wegmann M, Nagendra H, Turner W (2014a) Satellite remote sensing for applied ecologists: opportunities and challenges Journal of Applied Ecology 51:839-848 doi:10.1111/1365-2664.12261

Pettorelli N, Ryan S, Mueller T, Bunnefeld N, Jedrzejewska Ba, Lima M, Kausrud K (2011) The Normalized Difference Vegetation Index (NDVI): unforeseen successes in animal ecology Climate Research 46:15-27

Pettorelli N, Safi K, Turner W (2014b) Satellite remote sensing, biodiversity research and conservation of the future Phil Trans R Soc B 369:20130190

Pettorelli N et al. (2016 - in press) Framing the concept of Satellite Remote Sensing Essential Biodiversity Variables: challenges and future directions Remote Sensing in Ecology and Conservation 2:122-131 doi:10.1002/rse2.15 
Phinn S, Roelfsema C, Dekker A, Brando V, Anstee J (2008) Mapping seagrass species, cover and biomass in shallow waters: An assessment of satellite multispectral and airborne hyper-spectral imaging systems in Moreton Bay

(Australia) Remote Sensing of Environment 112:3413-3425 doi:10.1016/j.rse.2007.09.017

Pijanowski B, Farina A (2011) Introduction to the special issue on soundscape ecology Landscape Ecology 26:1209-1211 doi:10.1007/s10980-011-9655-6

Pijanowski BC et al. (2011) Soundscape ecology: the science of sound in the landscape BioScience 61:203-216

Popescu VD, de Valpine P, Sweitzer RA (2014) Testing the consistency of wildlife data types before combining them: the case of camera traps and telemetry Ecology and Evolution 4:933-943 doi:10.1002/ece3.997

Proença $\mathrm{V}$ et al. (2016 (in press)) Global biodiversity monitoring: from data sources to Essential Biodiversity Variables Biological Conservation

Raiteri R, Grattarola M, Berger R (2002) Micromechanics senses biomolecules Materials Today 5:22-29 doi:http://dx.doi.org/10.1016/S1369-7021(02)05139-8

Rich LN et al. (2014) Comparing capture-recapture, mark-resight, and spatial markresight models for estimating puma densities via camera traps Journal of Mammalogy 95:382-391

Rocchini D et al. (2016) Satellite remote sensing to monitor species diversity: potential and pitfalls Remote Sensing in Ecology and Conservation 2:25-36 doi:10.1002/rse2.9

Rowcliffe JM, Carbone C, Jansen PA, Kays R, Kranstauber B (2011) Quantifying the sensitivity of camera traps: an adapted distance sampling approach Methods in Ecology and Evolution 2:464-476 doi:10.1111/j.2041-210X.2011.00094.x

Rowcliffe JM, Carbone C, Kays R, Kranstauber B, Jansen PA (2012) Bias in estimating animal travel distance: the effect of sampling frequency Methods in Ecology and Evolution 3:653-662 doi:10.1111/j.2041-210X.2012.00197.x

Rowcliffe JM, Field J, Turvey ST, Carbone C (2008) Estimating animal density using camera traps without the need for individual recognition Journal of Applied Ecology 45:1228-1236 doi:10.1111/j.1365-2664.2008.01473.x

Sánchez-Gendriz I, Padovese L (2016) Underwater soundscape of marine protected areas in the south Brazilian coast Marine pollution bulletin 105:65-72

Schäfer RB, von der Ohe PC, Rasmussen J, Kefford BJ, Beketov MA, Schulz R, Liess $M(2012)$ Thresholds for the Effects of Pesticides on Invertebrate Communities and Leaf Breakdown in Stream Ecosystems Environmental science \& technology 46:5134-5142 doi:10.1021/es2039882

Schietti J et al. (2014) Vertical distance from drainage drives floristic composition changes in an Amazonian rainforest Plant Ecology \& Diversity 7:241-253

Schmeller D (2008) European species and habitat monitoring: where are we now? Biodiversity and Conservation 17:3321-3326

Schmeller D et al. (2008a) Determination of national conservation responsibilities for species conservation in regions with multiple political jurisdictions Biodiversity and Conservation 17:3607-3622

Schmeller D, Henle K, Loyau A, Besnard A, Henry P-Y (2012a) Bird-monitoring in Europe - a first overview of practices, motivations and aims Nature Conservation 2:41-57 doi:10.3897/natureconservation.2.3644

Schmeller DS, Bridgewater P (2016) The Intergovernmental Platform on Biodiversity and Ecosystem Services (IPBES): progress and next steps Biodiversity and Conservation 25:801-805 doi:10.1007/s10531-016-1095-9

Schmeller DS, Evans D, Lin YP, Henle K (2014) The national responsibility approach to setting conservation priorities - recommendations for its use Journal for Nature Conservation 22:349-357 
Schmeller DS, Gruber B, Budrys E, Framsted E, Lengyel S, Henle K (2008b) National responsibilities in European species conservation: A methodological review Conservation Biology 22:593-601

Schmeller DS, Henle K, Loyau A, Besnard A, Henry P-Y (2012b) Bird-monitoring in Europe - a first overview of practices, motivations and aims Nature Conservation 2:41-57

Schmeller DS et al. (2009) Advantages of Volunteer-Based Biodiversity Monitoring in Europe Conservation Biology 23:307-316

Schmeller DS et al. (2015) Towards a global terrestrial species monitoring program Journal for Nature Conservation 25:51-57

Schmeller DS, Maier A, Bauch B, Evans D, Henle K (2012c) National responsibilities for conserving habitats - a freely scalable method Nature Conservation 3:21-44

Schmeller DS et al. (2017) Case Studies of Capacity Building for Biodiversity Monitoring. In: Walters M, Scholes RJ (eds) The GEO Handbook on Biodiversity Observation Networks. Springer Nature, Cham, Switzerland, pp 309-326. doi:10.1007/978-3-319-27288-7_13

Schmiedel $U$ et al. (2016) Contributions of paraecologists and parataxonomists to research, conservation, and social development Conservation Biology 30:506519

Schmiedel U et al. (2010) Patterns and dynamics of vascular plant diversity along the BIOTA transects in southern Africa Biodiversity in southern Africa 2:118-135

Scott SM, James D, Ali Z (2006) Data analysis for electronic nose systems Microchimica Acta 156:183-207

Secades C, O'Connor B, Brown C, Walpole M (2014) Earth Observation for Biodiversity Monitoring: A review of current approaches and future opportunities for tracking progress towards the Aichi Biodiversity Targets. Technical Series No. 72. Montreal, Canada

Sheil D, Mugerwa B, Fegraus EH (2013) African golden cats, citizen science, and serendipity: tapping the camera trap revolution South African Journal of Wildlife Research 43:74-78

Simpson R, Page KR, De Roure D Zooniverse: observing the world's largest citizen science platform. In: Proceedings of the 23rd International Conference on World Wide Web, 2014. ACM, pp 1049-1054

Smith JW, Pijanowski BC (2014) Human and policy dimensions of soundscape ecology Global Environmental Change 28:63-74 doi:http://dx.doi.org/10.1016/i.gloenvcha.2014.05.007

Stapleton S, LaRue M, Lecomte N, Atkinson S, Garshelis D, Porter C, Atwood T (2014) Polar Bears from Space: Assessing Satellite Imagery as a Tool to Track Arctic Wildlife Plos One 9:e101513

Stepanian PM, Chilson PB, Kelly JF (2014) An introduction to radar image processing in ecology Methods in Ecology and Evolution 5:730-738 doi:10.1111/2041210x.12214

Swaay Cv, Warren M (2003) Prime butterfly areas in Europe: priority sites for conservation. Ministry of Agriculture, Nature Management and Fisheries,

Tape KD, Gustine DD (2014) Capturing Migration Phenology of Terrestrial Wildlife Using Camera Traps BioScience doi:10.1093/biosci/bit018

Thomsen PF, Kielgast J, Iversen LL, Moller PR, Rasmussen M, Willerslev E (2012) Detection of a diverse marine fish fauna using environmental DNA from seawater samples Plos One 7:e41732

Tittensor DP et al. (2014) A mid-term analysis of progress towards international biodiversity targets Science 14:241-244 
Tonkin JD, Arimoro FO, Haase P (2016) Exploring stream communities in a tropical biodiversity hotspot: biodiversity, regional occupancy, niche characteristics and environmental correlates Biodiversity and Conservation 25:975-993

Turner W (2013) Satellites: Make data freely accessible Nature 498:37-37

Turner W et al. (2015) Free and open-access satellite data are key to biodiversity conservation Biological Conservation 182:173-176

Van Donk E, Peacor S, Grosser K, De Senerpont Domis LN, Lürling M (2016) Pharmaceuticals May Disrupt Natural Chemical Information Flows and Species Interactions in Aquatic Systems: Ideas and Perspectives on a Hidden Global Change. In: de Voogt P (ed) Reviews of Environmental Contamination and Toxicology Volume 238. Springer International Publishing, Cham, pp 91-105. doi:10.1007/398 20155002

van Swaay CAM, Nowicki P, Settele J, van Strien AJ (2008) Butterfly Monitoring in Europe - a blueprint for international monitoring schemes? Biodiversity and Conservation 17:3455-3469

Vandzinskaite D, Kobierska H, Schmeller DS, Grodzińska-Jurczak M (2010) Cultural Diversity Issues in Biodiversity Monitoring-Cases of Lithuania, Poland and Denmark Diversity 2:1130-1145

Vohland K, Nadim T (2015) Ensuring the success of IPBES: between interface, market place and parliament Philosophical Transactions of the Royal Society B: Biological Sciences 370:20140012

Wabnitz CC, Andréfouët S, Torres-Pulliza D, Müller-Karger FE, Kramer PA (2008) Regional-scale seagrass habitat mapping in the Wider Caribbean region using Landsat sensors: Applications to conservation and ecology Remote Sensing of Environment 112:3455-3467

Wiggins SM, Hildebrand JA High-frequency Acoustic Recording Package (HARP) for broad-band, long-term marine mammal monitoring. In: Underwater Technology and Workshop on Scientific Use of Submarine Cables and Related Technologies, 2007. Symposium on, 2007. IEEE, pp 551-557

Yahara T et al. (2014) Developing a Regional Network of Biodiversity Observation in the Asia-Pacific Region: Achievements and Challenges of AP BON. In: Integrative Observations and Assessments. Springer, pp 3-28

Yoccoz NG, Nichols JD, Boulinier T (2001) Monitoring of biological diversity in space and time Trends in Ecology \& Evolution 16:446-453

Yoccoz NG, Nichols JD, Boulinier T (2003) Monitoring of biological diversity - a response to Danielsen et al Oryx 37:410-410

Zampoukas N, Piha H, Bigagli E, Hoepffner N, Hanke G, Cardoso AC (2013) Marine monitoring in the European Union: How to fulfill the requirements for the marine strategy framework directive in an efficient and integrated way Marine Policy 39:349-351 doi:10.1016/j.marpol.2012.12.004 
Figure legends:

Figure 1: Framework for Biodiversity Observation Networks (BONs) to build capacity in biodiversity monitoring.

Figure 2: Framework for capacity building in biodiversity monitoring with regard to the type of monitoring program, including extensive and intensive monitoring schemes, ecological studies, and remote sensing.

Figure 3: Recommendations for capacity building in volunteer-based / communitybased monitoring. 
Figure 1: Framework for Biodiversity Observation Networks (BONs) to build capacity in biodiversity monitoring.

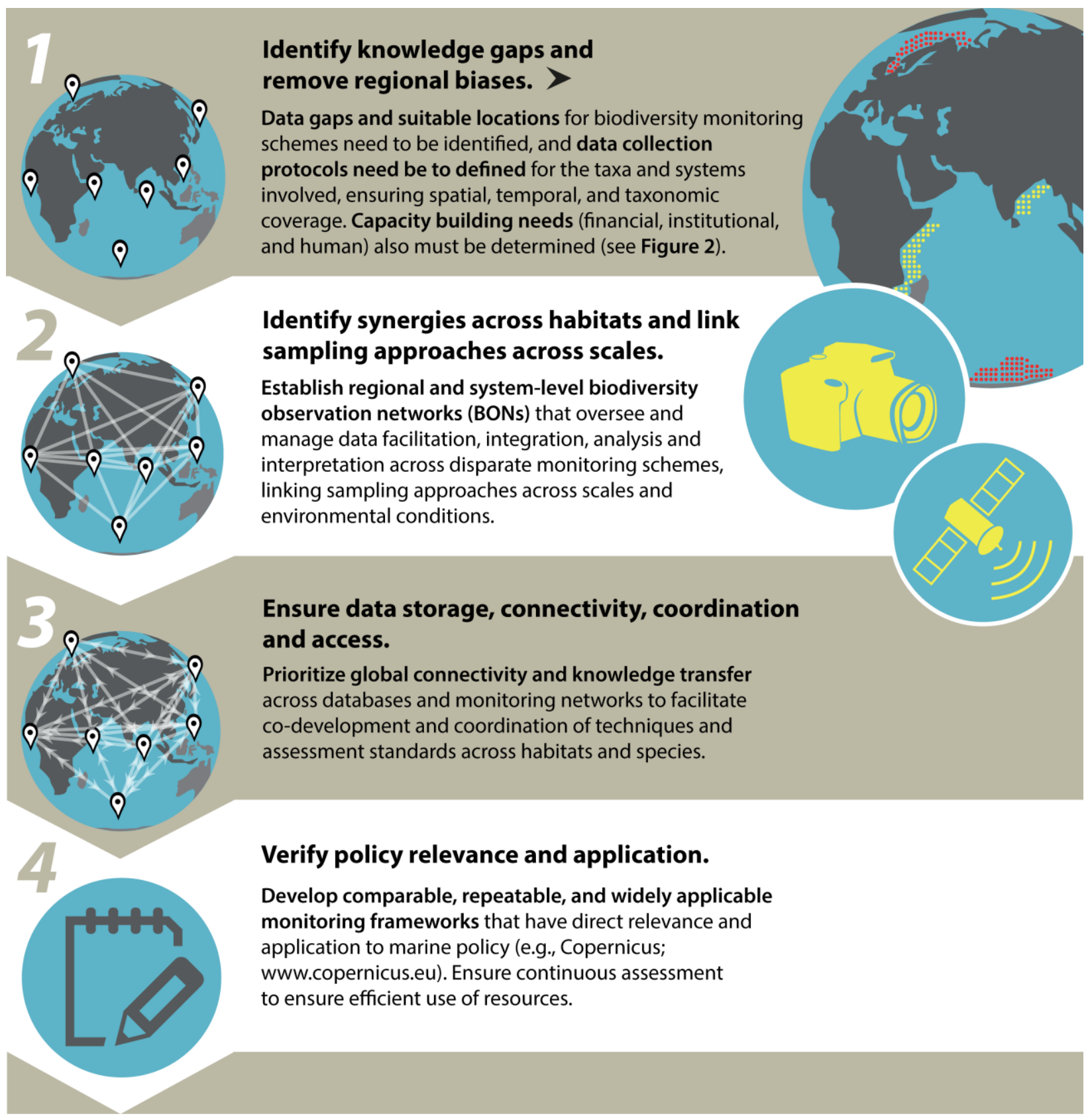


Figure 2. Framework for capacity building in biodiversity monitoring with regard to the monitoring scheme in question.

\begin{tabular}{|c|c|c|c|c|}
\hline & Extensive schemes & Intensive schemes & Ecological studies & Remote sensing (RS) \\
\hline Spatial coverage & High & Low & High & Very high \\
\hline Effort/site & Low & High & Low-high & Low \\
\hline Time investment & Long-term & Long-term & Short-term & Medium to long-term \\
\hline $\begin{array}{l}\text { Monitoring } \\
\text { skills/ecological } \\
\text { knowledge needed }\end{array}$ & Often basic & Advanced & Advanced & Very advanced \\
\hline $\begin{array}{l}\text { Resulting EBVs } \\
\text { relating to: }\end{array}$ & $\begin{array}{l}\text { Species populations, } \\
\text { Community } \\
\text { composition }\end{array}$ & Multiple EBV classes & Multiple EBV classes & $\begin{array}{l}\text { Ecosystem structure, } \\
\text { Ecosystem function }\end{array}$ \\
\hline & \multicolumn{4}{|c|}{ Example capacity needs } \\
\hline People & $\begin{array}{l}\text { NGOs } \\
\text { Citizen scientists } \\
\text { Volunteer networks }\end{array}$ & $\begin{array}{l}\text { NGOs } \\
\text { Para-ecologists } \\
\text { Trained professionals }\end{array}$ & $\begin{array}{l}\text { Para-ecologists } \\
\text { Technical field staff } \\
\text { Trained professionals }\end{array}$ & $\begin{array}{l}\text { Trained } \\
\text { professionals in RS \& } \\
\text { biodiversity/ecology }\end{array}$ \\
\hline Skills & Basic taxon ID & $\begin{array}{l}\text { Advanced taxon ID } \\
\text { Environment (e.g. pH, } \\
\text { temperature, chemical } \\
\text { composition, plant } \\
\text { coverage, etc.) }\end{array}$ & $\begin{array}{l}\text { Advanced taxon ID } \\
\text { Advanced survey } \\
\text { design } \\
\text { Monitoring drivers of } \\
\text { change }\end{array}$ & $\begin{array}{l}\text { Coding } \\
\text { Knowledge of } \\
\text { specialist software }\end{array}$ \\
\hline $\begin{array}{l}\text { Equipment/ } \\
\text { technology }\end{array}$ & $\begin{array}{l}\text { Easy-to-use } \\
\text { monitoring devices } \\
\text { (phone apps, bat } \\
\text { monitors, etc), simple } \\
\text { field guides }\end{array}$ & $\begin{array}{l}\text { Advanced monitoring } \\
\text { devices (camera traps, } \\
\text { soundscaping, eDNA kits, } \\
\text { submersibles, etc.) }\end{array}$ & $\begin{array}{l}\text { Advanced monitoring } \\
\text { devices (camera } \\
\text { traps, soundscaping, } \\
\text { eDNA kits, } \\
\text { submersibles, etc.) }\end{array}$ & $\begin{array}{l}\text { RS software } \\
\text { Access to RS data } \\
\text { Very large data } \\
\text { storage \& } \\
\text { processing power }\end{array}$ \\
\hline
\end{tabular}


Figure 3: Capacity building in volunteer-based / community-based monitoring

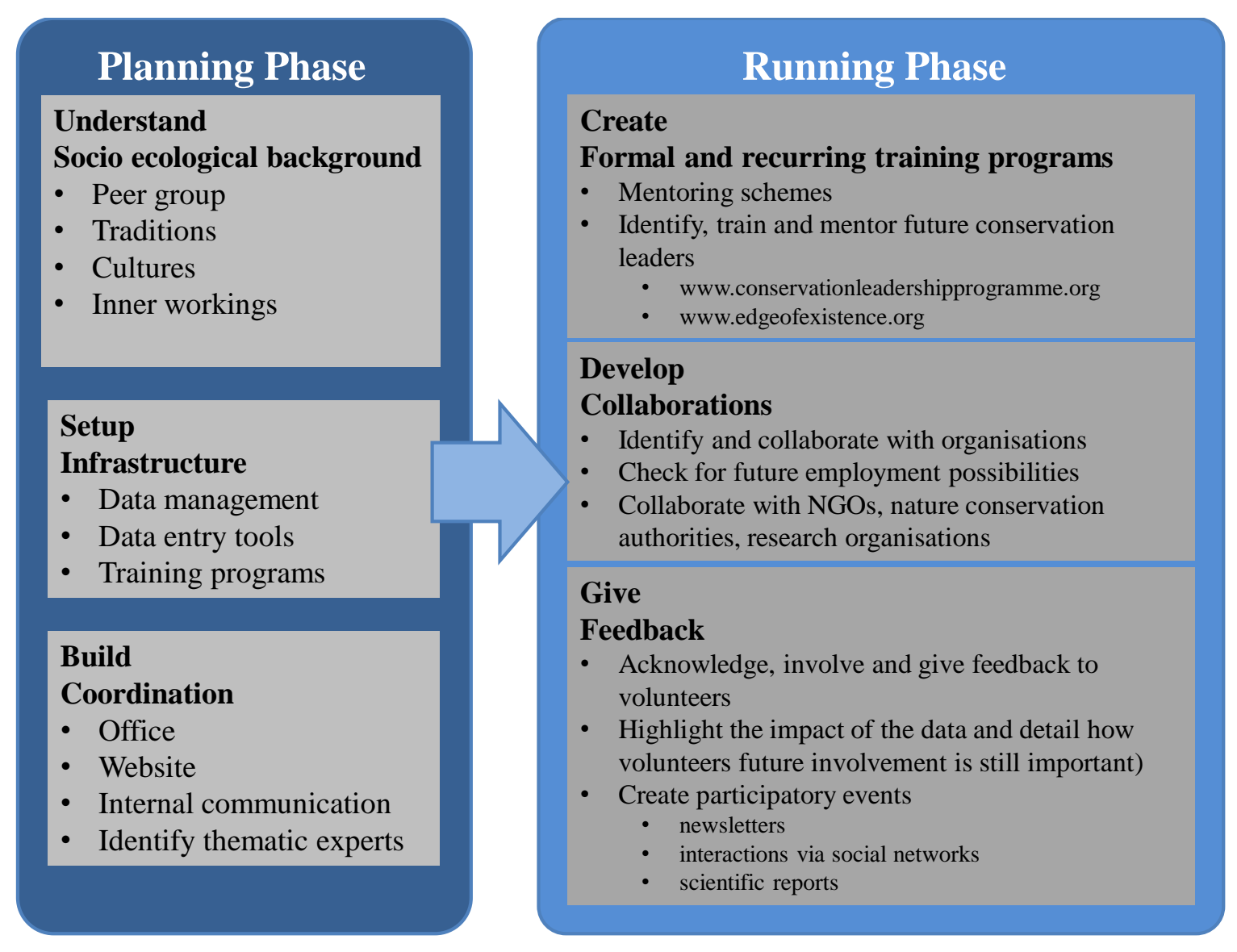

